\title{
Comentario y síntesis sobre temas tratados en el XXIV Congreso Nacional de Contadores Públicos del Perú 2014
}

\author{
José María ZEVALLOS
}

El auspicioso evento se llevó a cabo en la hermosa y primaveral ciudad de los nobles caballeros del León de Huánuco, los días 27; 28; 29 y 30 de agosto de 2014, en la sede de la dinámica Universidad Nacional Hermilio Valdizán, organizada y patrocinada por la Junta de Decanos de Colegios de Contadores Públicos del Perú, Colegio de Contadores Públicos de Huánuco, por la Asociación Interamericana de Contabilidad (AIC), por la International Federation of Accountants (IFAC) y por el Comité de Integración Latino Europa-América (CILEA), con una nutrida participación de Contadores de todo el Perú e invitados de países hermanos.

La denominación del Congreso estuvo inspirado en el importante rol que cumple el profesional Contador Público al servicio de las diversas organizaciones del país, consecuentemente se tituló: LIDERAZGO DEL CONTADOR PÚBLICO IMPULSANDO EL DESARROLLO EMPRESARIAL, SOCIAL Y ECONÓMICO DEL PERÚ.

En ese contexto los organizadores presentaron un nutrido programa de conferencistas, siendo la primera una conferencia magistral, con el tema "PERSPECTIVA ECONÓMICA Y DESARROLLO HUMANO EN EL PERÚ", expuesto por el Eco. Pedro Pablo Kuczynski Godard, ex ministro de Economía y Finanzas, de cuyo mensaje resaltamos lo siguiente:

- El conferencista mencionó que el Perú después de un período de 12 a 13 años de crecimiento económico constante en base a diversas reformas desde el año 90, alcanzó un importante calificativo, pero adujo que, aún somos todavía pobres. Dijo que la política del momento ha frenado la economía, se presume que será transitorio. A nivel global hay un hecho dominante, Europa no está creciendo desde hace 6 a 7 años, debido a la recesión europea, el crédito financiero no aumenta, sigue bajando en el sector privado. Lo preocupante para los europeos es la deflación. En el Perú no pasa esto.

- Señaló además que, el problema económico actual del país, se traduce a dos causas: interna y externa. Interna, inestabilidad política y externa, 
principalmente la caída del precio del oro, que es nuestra segunda exportación. Se preguntó, ¿cómo salir de este problema? Generando estabilidad y confianza, promoviendo las inversiones que pueden ayudar a crecer, tales como proyectos mineros, el agro, las exportaciones, etc.

- Recomendó que el actual Gabinete Ministerial debe estar respaldado, para que ya no haya más cambios hasta el final del gobierno.

- Propuso un tema muy importante para los Contadores, coadyuvar en la formalización de las empresas, el $80 \%$ de los trabajadores son informales, no tienen seguro ni fondo de pensiones. La informalidad debe disminuir, posiblemente podría manejarse entre el 15 al 20\%. El Estado hace malabares para recaudar impuestos, por lo que es necesario una reforma tributaria, bajar el IGV y el IR, lo cual tiene que ir acompañado por programas para formalizar el mercado de trabajo, creación de Instituciones Tecnológicas. La informalidad genera empleados mal pagados.

- Finalmente culminó su conferencia, recomendando que un gran tema de diálogo debe ser la formalización de la actividad laboral.

Otra importante conferencia que tuvo gran atención del auditorio fue el Tema: "HERRAMIENTAS FINANCIERAS PARA EL DESARROLLO ECONOMICO DE LAS PYMES”, a cargo del expositor: CPC Freddy Llanto Armijo.

"Resaltó los temas NIIF para PYMES. Mencionó que en el Perú no están reglamentadas las NIIF para PYMES, en Colombia sí. Aplicar NIIF es ver la realidad, porque la Contabilidad basada en asuntos tributarios ha sido una falacia".

Una conferencia magistral que motivó el interés en el aspecto de control nos entregó el brillante expositor doctor Carlos Pastor Carrasco, con el tema: “COBIT: UNA METODOLOGÍA PARA LA GESTIÓN Y CONTROL DE LA INFORMACIÓN Y TECNOLOGÍA DE LA INFORMACIÓN, RIESGO Y VULNERABILIDAD PARA EL PROCESO DE UNAAUDITORÍA EFICAZ”.

"El interlocutor afirmó que se avecina cambios tecnológicos muy fuertes, para ello debemos estar preparados. Hizo mención de la Ley de Murphy, de los conceptos del valor, del grado de utilidad o aptitud de las cosas para aplicar, del objeto de control, de la evolución del enfoque de auditoría, de cómo implementar la auditoría. Comentó sobre las normas internacionales de auditoría, ampliando el contenido de los COBIT. COBIT como objetivo de las técnicas de información (TI). Mencionó que los COBIT han tenido varias versiones: el año 1996 la primera edición, en 1998 la segunda edición con el añadido "control", en la tercera edición el año 2000 se publicó "directrices de gestión”, en diciembre de 2005 la cuarta edición, en mayo de 2007 la revisión 4.1. Fue lanzado, en junio de 2012 COBIT 5, en diciembre de 2012 y en junio de 
2013, fueron incorporados un documento para la seguridad de la información y para la garantía, respectivamente. Finalmente adujo que el COBIT, como objeto de calidad para la información de control de información: Analiza como ocurre la creación y el final de los procesos, ayuda en la comprensión y gestión de riesgos, ayuda a salvar las brechas entre los riesgos de los negocios y las necesidades de control, asegura la investigación de los sistemas, nace en base del Balance Score Card y la información que proporciona COBIT es para alcanzar los objetivos del negocio".

Causó especial atención la conferencia magistral con el tema: "LA PRUEBA PERICIAL" expuesta por la doctora Jeri Glori Ramón Ruffner de Vega, presidenta de la Asociación de Peritos del Perú, con mensajes relevantes tales como:

- No hay transacción que se haga si no están las evidencias.

- Nadie puede realizar contabilidad, auditoría, peritaje, si no se tiene el documento que lo sustente.

- La prueba es fundamental, es la comprobación de hechos ocurridos, afirmando y/o negando por una de las partes, es la demostración de la verdad.

- La expositora, define la Pericia, como un análisis de hechos desde el inicio hasta el final.

- Además agregó, que debe incidirse en la importancia de la prueba en todos los aspectos jurídicos. La contabilidad es completamente legalista.

- Mencionó que la Prueba Pericial, es la opinión fundamentada de una persona especializada para conocimiento del juez; el perito es el especialista y el dictamen es la opinión fundamentada. La prueba pericial verifica hechos, suministras reglas técnicas para una mejor aplicación de hechos para el juez. La pericia es concluyente, no hay término medio. Para que la pericia tenga valor la documentación debe ser original o fedeteada.

- Finalmente, a manera de reflexión informó que en el Poder Judicial existen miles de expedientes paralizados por falta de peritos. Los jueces requieren tal apoyo para una correcta administración de la justicia.

Debo resaltar otra interesante conferencia magistral con el tema:'LA CONTABILIDAD Y LA AUDITORÍA EN EL PASADO, PRESENTE Y EL FUTURO", expuesta por el doctor Adrián Flores Konja, incidiendo en lo siguiente:

- El Contador, tiene que ser conocedor de todas las normas contables, leyes y técnicas que se aplican en el sector público y privado, debe cumplir su profesión de acuerdo a ley, de lo contrario incurre en responsabilidad civil y penal. 
- La contabilidad es gobierno, ahora y siempre, el Contador es un líder.

- La contabilidad debe replantear sus objetivos, se debe reordenar y reforzar la formación de futuros contadores para hacer frente a la necesidad de mayor información contable.

- Se debe atender las recomendaciones de organismos rectores de la contabilidad internacional para implementar los nuevos planes curriculares.

- Es imperativo armonizar los conocimientos contables a nivel global y darle la debida importancia a la ética profesional. Que los Colegios Profesionales garanticen la unidad profesional y el cumplimiento de la ética profesional.

- Para finalizar, mencionó que podemos ser muy buenos profesionales pero lo fundamental es la Conducta Ética.

También, la conferencia magistral con el tema: "INVESTIGACIÓNCIENTÍFICA CUALITATIVA, ALTERNATIVA PARA EL DESARROLLO CIENTÍFICO DE LAS CIENCIAS CONTABLES Y FINANCIERAS”, expuesta por la doctora Angélica Arroyo Morales, tuvo gran impacto, resaltamos algunos mensajes:

- La profesión del Contador Público es una las profesiones más apasionantes que puede haberse creado, su participación es vital en la toma de decisiones.

- La investigación contable es la base de los eventos y la presencia de brillantes expositores.

- Debemos realizar con gran pasión la investigación contable. Necesitamos realizar el desarrollo científico con investigación contable.

En la brillante conferencia magistral con el tema: "LA FORMACIÓN DEL CONTADOR PÚBLICO INTERAMERICANO, HACIA UNA CURRÍCULA HOMOGÉNEA", expuesto por el doctor Ricardo José María Pahlen Acuña, de Argentina, se resalta lo siguiente:

- Debería haber un currículo básico contable en Latinoamérica.

- La contabilidad es el centro, nadie puede determinar nada si no somos nosotros.

- El objetivo de la profesión es brindar información contable en todas sus formas.

- El objetivo de la enseñanza, es formar y graduar a los contadores con habilidades y aptitudes para ejecutar tareas de la profesión de acuerdo a la legislación vigente, diseñar, implementar y dirigir sistemáticamente la registración e información contable que permita la toma de decisiones para el logro de los objetivos de la organización.

- En la Argentina la Contabilidad Gubernamental no es obligatoria, sin embargo el 38\% de los contadores trabajan en el sector público. 
- Es necesario promover el desarrollo ético en el ejercicio de la profesión.

- Debe incluirse en el plan curricular las recomendaciones de IFAC, también, las Prácticas Profesionales Supervisadas y las áreas contables: Contabilidad e Impuestos, Administración y Técnicas de Información Contable, Economía, área Jurídica, Matemática y área Humanística.

- A través del AIC, se pueden realizar acreditación de la carrera en convenio con CACECA.

Una de las últimas conferencias magistrales estuvo relacionado con el tema: "RETOS DEL CONTROL GUBERNAMENTAL FRENTE A LA CORRUPCION", a cargo del CPC Fuad Khoury Salazar, Contralor General de la República, quien enfatizó lo siguiente:

- El Contador Público tiene una enorme responsabilidad social, el de tener los registro legales en contra de la corrupción. Cuando los contadores públicos no presentan la información adecuada, los dictámenes son con salvedades o con abstención de opinión.

- Argumentó que, los contadores públicos del Perú y la Contraloría, son una permanente amenaza contra la corrupción.

- La buena práctica contable comenzando por el control interno, lo es todo; sin embargo en el Sector Público el control interno es casi nula, por la falta de capacitación y el desinterés.

- El control interno es el sistema inmunológico contra la corrupción.

- Propuso una fórmula para determinar la corrupción: Monopolio + discrecionalidad - rendición de cuentas = corrupción.

- El primer problema que afecta al país es la reelección, seguido de la corrupción.

- Lo más grave en el país es la ineficiencia en la administración pública y la corrupción, lo cual genera pobreza y menos crecimiento del PBI. Existe impunidad y no se castiga a los corruptos.

- La falta de ética genera corrupción, la corrupción afecta la competitividad, a menor competitividad mayor pobreza. Hay que propender a enseñar los valores. Estamos en una crisis de valores.

- La lucha contra la corrupción debe basarse en: compromiso al más alto nivel gubernamental, legislación en $360^{\circ}$, profunda reingeniería en la gestión pública, transparencia en la rendición de cuentas, sector privado con responsabilidad social corporativa y prácticas de anticorrupción, educación en valores y medición y seguimiento.

- Aseveró que la corrupción atenta contra los derechos humanos. 
Este Congreso Nacional de Contadores Públicos del Perú 2014, tuvo una nutrida participación, donde se abordó temas de sumo interés para la profesión en veintiocho conferencias magistrales, de los cuales se han comentado algunas de ellas, que a mi opinión han resaltado. Este evento ha trascendido a nivel nacional e internacional, con el patrocinio de organismos contables internacionales tales como IFAC, AIC y CILEA.

La Junta de Decanos de Colegios de Contadores Públicos del Perú, como máximo organismo representativo de la Profesión Contable en el país y en el exterior por mandato de la Ley 13253, Decreto Ley 25892 y su Reglamento aprobado por Decreto Supremo No. 008-93-JUS, después de sendas discusiones de las áreas pertinentes, se llegó a determinar las conclusiones, de las cuales señalo las más importantes:

1. El Perú no cuenta con un presupuesto importante para el apoyo y desarrollo de la investigación contable.

2. Se denota carencia y desconocimiento de las técnicas y metodologías de la investigación científica, por cuanto la investigación contable es incipiente en el país.

3. La Auditoría Social, constituye un proceso de participación ciudadana y la Auditoría Ambiental es un instrumento de gestión, para su desarrollo es necesario conocer las políticas estatales orientados a los programas sociales y la política ambiental que debe regular el comportamiento de las organizaciones.

4. El aumento de los niveles de fraude y corrupción e impunidad en los sectores público y privado hace necesario la Auditoría Forense, como una fórmula idónea para prevenir, disuadir, detectar, investigar y combatir a tiempo este flagelo, por cuanto la delincuencia organizada utiliza métodos y tecnología de punta para perpetrar sus crímenes.

5. El modelo de Administración Financiera que se opera en el sector público permite un mejor control interno.

6. En los últimos años más del $90 \%$ de los nuevos Contadores Públicos obtuvieron su título profesional mediante la modalidad de Cursos de Actualización y sólo el 10\% a través de exámenes de suficiencia y tesis.

7. La calidad de la formación profesional que se brinda en el sistema universitario no fue ni será la más adecuada mientras la acreditación universitaria sea voluntaria.

8. Dada la velocidad de cambios impuestos por la globalización, los usuarios requieren, cada vez más, eficaces herramientas de gestión, hechas a medida de cada empresa.

9. Para cumplir la delicada responsabilidad del Contador Público dispone de dos instrumentos legales sustantivos: el Código de Ética del Contador 
Público Mundial aprobado por IFAC y el Código de Ética del Contador Público del Perú, normatividad que regula el comportamiento en el ejercicio profesional del Contador Público.

10. Escasa difusión de la esencia de ambos códigos a través de los Colegios de Contadores Públicos del Perú y limitada enseñanza de la moral y ética en las Facultades de Ciencias Contables y Financieras.

11. Gran número de contribuyentes emplean personas que no son profesionales contables, con el objeto de reducir costos de cumplimiento o en algunos casos, evadir impuestos, lo cual genera mayor informalidad.

12. Las Empresas actuales se desarrollan en un ambiente competitivo por lo que es necesario que la información financiera sea con leguaje y estándares comunes, con el uso de las herramientas financieras que apoyen la toma de decisiones combinados con el presupuesto.

13. Las tendencias de estándares que van surgiendo en el campo de la Tecnología de información, para la formación de Contadores Públicos, obliga que los profesionales contables deben actualizarse permanentemente.

Me permito, a través de este medio congratular a los organizadores del Congreso por el éxito de este magno evento, así como a los expositores y participantes, augurando que certámenes de esta naturaleza sean más continuos y se difundan en beneficio de la profesión contable. 


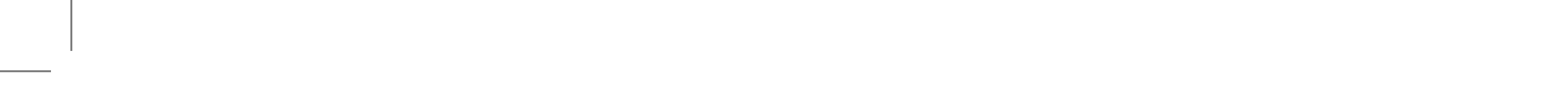

